\title{
Influência da idade da muda de Eucalyptus grandis no desenvolvimento da lagarta-rosca Nomophila sp. ${ }^{(1)}$
}

\author{
José Cola Zanuncio(2), Marcos Franklin Sossai(2), Teresinha Vinha Zanuncio(2) e César Augusto Domingues Teixeira ${ }^{(2)}$
}

\begin{abstract}
Resumo - O objetivo deste trabalho foi estudar a influência da idade das mudas de Eucalyptus grandis (Myrtaceae) no desenvolvimento da lagarta-rosca Nomophila sp. (Lepidoptera: Pyralidae). Esse inseto foi alimentado em laboratório $\left(24 \pm 2^{\circ} \mathrm{C}, 80 \pm 15 \%\right.$ de UR e fotofase de 12 horas) com folhas de eucalipto com 20-30 dias ou com 50-60 dias de idade. Os parâmetros observados foram: número, duração e caracterização dos estádios, largura da cápsula cefálica, comprimento do corpo, duração da fase larval, relação entre número de estádios e o sexo, viabilidade e comportamento das lagartas de Nomophila sp. Esse inseto mostrou melhor desenvolvimento em todos os parâmetros observados, em mudas de eucalipto com 20-30 dias do que em mudas com 50-60 dias de idade, quando o caule está mais enrijecido. Isto reforça a necessidade de se realizar uma adubação balanceada nas mudas de $E$. grandis, como forma de acelerar seu desenvolvimento, e torná-las morfologicamente menos favoráveis ao desenvolvimento das lagartas de Nomophila sp.
\end{abstract}

Termos para indexação: viveiro florestal, biologia florestal, eucalipto, inseto-praga.

Influence of the age of Eucalyptus grandis seedlings in the development of Nomophila sp.

Abstract - The influence of the age of Eucalyptus grandis (Myrtaceae) seedlings in the development of Nomophila sp. (Lepidoptera: Pyralidae) was studied. The insect was fed in laboratory at $24 \pm 2^{\circ} \mathrm{C}$, $80 \pm 15 \%$ of RH and photophase of 12 hours with 20-30 days or 50-60 days old E. grandis leaves. Observed parameters were: number, duration and characterization of each instar, width of head capsule, length of the body, duration of the larval stage, relationship between number of instars and sex of adults, viability and behavior of Nomophila sp. caterpillars. This insect showed better development with 20-30 days old E. grandis seedlings than those with 50-60 days old E. grandis seedlings, which have harder stems. This reinforces the need to grow Eucalyptus seedlings in good fertility conditions aiming to increase their development which could reduce damage level by Nomophila sp.

Index terms: forest nursery, forest biology, eucalyptus, insect-pests.

\section{Introdução}

A produção de mudas em viveiros constitui uma das fases mais importantes do processo de implantação de povoamentos florestais, pois mudas de baixa qualidade podem comprometer todas as operações seguintes (Gallo et al., 1978). Por outro lado, mudas com padrão adequado de qualidade apresentam melhores condições de crescimento e de compe-

(1) Aceito para publicação em 14 de junho de 2000 .

(2) Universidade Federal de Viçosa (UFV), Dep. de Biologia Animal (DBA), CEP 36571-000 Viçosa, MG. E-mail zanuncio@ufv.br, cesar@alunos.ufv.br, sossai@alunos.ufv.br tição por fatores como água, luz e nutrientes. Segundo Paiva \& Gomes (1995) tais mudas devem apresentar, no momento de serem plantadas no campo, entre outras características, sistema radicular bem formado, com raiz principal reta sem enovelamento e raízes secundárias bem distribuídas, propiciando uma maior resistência das mesmas a fatores adversos.

A incidência de insetos-praga pode levar à perda de um grande número de mudas por morte ou deformações, além de reduzir a resistência das mesmas a doenças. No viveiro, os principais insetos que danificam mudas de eucalipto são lagartas-rosca dos gêneros Agrotis e Spodoptera (Lepidoptera: Noctuidae); grilos, Gryllus assimilis (Fabricius, 1775) 
(Orthoptera: Gryllotalpidae); paquinhas, Gryllotalpa hexadactyla (Perty, 1832) (Orthoptera: Gryllotalpidae) e cupins do gênero Sintermes (Isoptera: Termitidae) (Anjos et al., 1986).

Dentre as lagartas que tem causado danos às mudas em viveiros florestais, destacam-se Spodoptera frugiperda (Smith \& Abbot, 1797), Spodoptera latifascia (Walker, 1856), Spodoptera eridania (Stoll, 1781), Agrotis repleta (Walker, 1857), Agrotis subterranea (Fabricius, 1794) e Agrotis ipsilon (Rottemburg, 1776). Enquanto isso, mudas de essências florestais como Pinus spp. (Coniferae), seringueira (Hevea brasiliensis, Euphorbiaceae), acácia-negra (Acacia decurrens, Leguminosae), bracatinga (Mimosa scabrella, Leguminosae), além de Eucalyptus spp., Eucalyptus grandis, Eucalyptus camaldulensis e Eucalyptus urophylla são constantemente atacadas por lagartas-rosca (Krug, 1963; Silva et al., 1968; Reis \& Hodges, 1976; Santos et al., 1980; Anjos et al., 1981; Berti Filho, 1981; Santos et al., 1985; Anjos et al., 1986). Na região de Viçosa, Minas Gerais, a lagarta-rosca Nomophila sp. tem causado danos em viveiros de eucalipto (Teixeira et al., 1999).

As lagartas-rosca ocorrem durante todo o ano, com picos populacionais em períodos de maior disponibilidade de mudas com poucos dias ou semanas de idade. Nessa situação, quando as mudas apresentam caules tenros, uma única lagarta pode cortar dezenas delas em uma noite (Anjos et al., 1986) e em condições favoráveis para essa praga, entre 50 a $100 \%$ das mudas podem ser destruídas ou severamente danificadas (Reis \& Hodges, 1976).

O objetivo deste trabalho foi estudar aspectos biológicos do ciclo de vida de Nomophila sp. (Lepidoptera: Noctuidae), alimentada com mudas de Eucalyptus grandis com 20-30 ou 50-60 dias de idade.

\section{Material e Métodos}

Este trabalho foi desenvolvido no insetário do Departamento de Biologia Animal da Universidade Federal de Viçosa (UFV), em Viçosa, Minas Gerais, em sala com 3,5 x $3,5 \times 3,0$ m, iluminada por dois conjuntos de quatro lâmpadas fluorescentes, tipo luz do dia, de 40 watts, dispostas no teto, com fotofase de 12 horas, temperatura de $24 \pm 2^{\circ} \mathrm{C}$ e umidade relativa de $80 \pm 15 \%$.
O número, duração e caracterização dos estádios, largura da cápsula cefálica, comprimento do corpo, duração da fase larval, relação entre número de estádios e o sexo, além da viabilidade e comportamento de lagartas de Nomophila sp. foram estudados, alimentando-se as mesmas com mudas de E. grandis com 20-30 dias (tratamento A) ou 50-60 dias (tratamento B). As lagartas de Nomophila sp. foram obtidas a partir de ovos de criação massal dessa espécie, mantida em laboratório em tubos de ensaio ( $20 \times 2 \mathrm{~cm})$, tampados com algodão hidrófilo. Essas lagartas receberam folhas nos dois primeiros estádios e folhas ou pedaços de caulículos de mudas de E. grandis, com idade de acordo com o respectivo tratamento, nos demais estádios. Cada repetição, em número de 30 , foi representada por uma lagarta de Nomophila sp. individualizada em um tubo de ensaio $(20 \times 2 \mathrm{~cm})$. Adultos de Nomophila sp. foram montados em mantas entomológicas e enviados para a USP-ESALQ para identificação.

As observações morfológicas e as medições das lagartas de Nomophila sp. foram feitas com lupa binocular, com aumento de 160x, aferida por lâmina graduada em décimos de milímetros. Essas lagartas foram manipuladas com pincéis finos.

No primeiro estádio, a cápsula cefálica e o comprimento do corpo das lagartas de Nomophila sp. foram medidos no primeiro ou segundo dia após a eclosão, enquanto nos demais isto foi feito logo após cada ecdise. Diariamente foram realizadas duas observações para se estabelecer a duração de cada estádio e a sobrevivência das lagartas de Nomophila sp. em cada um deles.

Foram registrados a localização, número, forma e coloração de manchas, pêlos e outras características do corpo das lagartas de Nomophila sp. nos diferentes estádios. Além disso, observações diárias foram feitas para se descrever algumas características comportamentais de repouso, movimento, refúgio, ecdise e alimentação das lagartas de Nomophila sp.

\section{Resultados e Discussão}

\section{Número e duração dos estádios, duração da fase larval e relação entre número de estádios e sexo}

Das 27 lagartas de Nomophila sp. do tratamento A que completaram a fase larval, 79,1\% apresentaram cinco estádios e 20,9\%, seis. Por outro lado, das 27 lagartas do tratamento B, 39,3\%, 53,6\% e 7,1\% apresentaram seis, sete e oito estádios, respectivamente (Tabela 1). No tratamento A, das 12 lagartas que originaram adultos machos, 11 concluíram a fase larval no quinto estádio e uma, no sexto; das 15 lagartas que originaram adultos fêmeas, 10 concluíram a fase 
Tabela 1. Porcentagem de lagartas $(\mathrm{n}=27)$ de Nomophila $\mathrm{sp}$. desenvolvidas até o VIII estádio e que deram origem a machos ou fêmeas, quando alimentadas com mudas de Eucalyptus grandis de 20-30 (tratamento A) ou 50-60 dias (tratamento B) de idade.

\begin{tabular}{|c|c|c|c|c|c|c|c|c|c|c|c|c|}
\hline \multirow[t]{2}{*}{ Tratamento $^{(1)}$} & \multicolumn{4}{|c|}{ Machos (\%) } & \multicolumn{4}{|c|}{ Fêmeas (\%) } & \multicolumn{4}{|c|}{ Média (\%) } \\
\hline & V & VI & VII & VIII & V & VI & VII & VIII & V & VI & VII & VIII \\
\hline A & 91,7 & $8,3^{(2)}$ & 0,0 & 0,0 & 66,6 & 33,4 & 0,0 & 0,0 & 79,1 & 20,9 & 0,0 & 0,0 \\
\hline B & 0,0 & 50,0 & 50,0 & 0,0 & 0,0 & 28,6 & 57,1 & $14,3^{(2)}$ & 0,0 & 39,3 & 53,6 & 7,1 \\
\hline
\end{tabular}

(1) A: das 27 lagartas que completaram a fase larval, 12 deram origem a machos e 15, a fêmeas; $\mathrm{B}$ : das 27 lagartas que completaram a fase larval, 20 deram origem a machos e sete, a fêmeas. ${ }^{(2)}$ Apenas uma lagarta completou este estádio.

larval no quinto estádio e cinco, no sexto. No tratamento $\mathrm{B}$, das 20 lagartas que originaram adultos machos, 10 concluíram a fase larval no sexto estádio e 10 , no sétimo; das sete lagartas que originaram adultos fêmeas, duas concluíram a fase larval no sexto estádio, quatro, no sétimo e uma, no oitavo. As lagartas de Nomophila sp., que deram origem a machos, apresentaram menor número de estádios. Tal variação do número de estádios ( 5 a 8 ) de Nomophila sp. em mudas de E. grandis difere de resultados de outros autores para uma espécie desse gênero. Johnson \& Duffield (1961) observaram cinco estádios para Nomophila noctuella (Denis e Schiffermuller, 1775) em mudas de Pinus sp. enquanto Felt (1893), Smith (1942), Mourikis \& VassilainaAlexopoulou (1970) observaram seis estádios, quando essa espécie foi alimentada com trevo-amarelo, alfafa ou dieta artificial, respectivamente.

A duração da fase larval de Nomophila sp. foi menor no tratamento A, pois no B algumas lagartas desse inseto permaneceram por uma ou mais semanas no mesmo estádio, especialmente no último, que foi, também, o mais longo no tratamento A. Nos demais estádios, em ambos os tratamentos, a duração de cada estádio não ultrapassou quatro dias (Tabela 2). No tratamento A, as lagartas de Nomophila sp. atingiram o estádio de pré-pupa em até três semanas, enquanto no $\mathrm{B}$ isto ocorreu em pelo menos um mês. No tratamento $B$, as lagartas completaram cada estádio com diferença máxima de dois dias. As lagartas com maior número de estádios apresentaram período larval mais longo. Lagartas que deram origem a machos apresentaram menor período larval que as que originaram fêmeas (Tabela 2). A maior duração da fase larval, especialmente do último estádio, concorda com relato de Mourikis \&
Vassilaina-Alexopoulou (1970), que observaram duração desse estádio de três a quatro e de 2,5 a três dias em $N$. noctuella alimentada com alfafa e dieta artificial, respectivamente. Esses autores obtiveram lagartas completamente desenvolvidas em 15-19 dias e Smith (1942) relata duração de 18 dias, para essa fase, enquanto lagartas de Nomophila sp. criadas com mudas de E. grandis de 20-30 ou 50-60 dias, levaram de 17,2-21,0 e de 29,9-37,0 dias para completar a fase larval.

Em dietas artificiais nutricionalmente balanceadas ou em condições de campo alimentada com plantas de ocorrência natural em regiões temperadas, como alfafa e trevo-amarelo, $N$. noctuella mostra número semelhante de estádios, mas menor duração da fase larval que a espécie de Nomophila estudada neste trabalho. Isto indica que esta espécie encontra-se, ainda, em fase de adaptação ao $E$. grandis, de forma semelhante a outros insetos em diferentes espécies de Eucalyptus, gênero exótico no continente americano (Zanuncio et al., 1993).

O estádio de pré-pupa foi menor no tratamento A e os machos, desse tratamento, apresentaram menor duração do período de ovo a adulto (Tabela 2). No estádio de pré-pupa as espécimes apresentavam o corpo encolhido, levemente curvado, com os segmentos do corpo enrugados e não mais se alimentavam de material verde. $O$ período de ovo a adulto foi de 32,5 e 50,13 dias, nos tratamentos A e B, respectivamente.

\section{Largura da cápsula cefálica, comprimento do corpo e caracterização morfológica}

Lagartas do tratamento A apresentaram maior largura da cápsula cefálica que as do $\mathrm{B}$, exceto no primeiro estádio (Tabela 3 ). Nos primeiros estádios, as 
Tabela 2. Duração dos estádios de Nomophila sp. alimentada com mudas de Eucalyptus grandis com 20-30 (A) ou 5060 dias (B), segundo o total de estádios e o sexo do adulto que originaram ${ }^{(1)}$.

\begin{tabular}{|c|c|c|c|c|c|c|c|c|c|}
\hline \multirow[t]{3}{*}{ Estádio $^{(2)}$} & \multirow{3}{*}{ Tratamento } & \multicolumn{8}{|c|}{ Duração do estádio (dias)/larva } \\
\hline & & \multicolumn{2}{|c|}{ V estádio } & \multicolumn{2}{|c|}{ VI estádio } & \multicolumn{2}{|c|}{ VII estádio } & \multicolumn{2}{|c|}{ VIII estádio } \\
\hline & & Macho & Fêmea & Macho $^{(3)}$ & Fêmea & Macho & Fêmea & Macho & Fêmea $^{(3)}$ \\
\hline \multirow[t]{2}{*}{ I } & A & $3,0 \pm 0,0$ & $2,8 \pm 0,2$ & 3,0 & $2,6 \pm 0,3$ & - & - & - & - \\
\hline & B & $-^{(4)}$ & - & $3,4 \pm 0,2$ & $3,5 \pm 0,5$ & $3,7 \pm 0,2$ & $3,7 \pm 0,3$ & - & 4,0 \\
\hline \multirow[t]{2}{*}{ II } & A & $2,3 \pm 0,1$ & $2,6 \pm 0,2$ & 3,0 & $2,2 \pm 0,2$ & - & - & - & - \\
\hline & B & - & - & $3,3 \pm 0,3$ & $3,0 \pm 0,0$ & $3,4 \pm 0,2$ & $3,0 \pm 0,0$ & - & 3,0 \\
\hline \multirow[t]{2}{*}{ III } & A & $2,7 \pm 0,2$ & $3,1 \pm 0,3$ & 2,0 & $3,2 \pm 0,4$ & - & - & - & - \\
\hline & B & - & - & $3,1 \pm 0,3$ & $3,0 \pm 0,0$ & $3,7 \pm 0,3$ & $2,8 \pm 0,3$ & - & 3,0 \\
\hline \multirow[t]{2}{*}{ IV } & A & $3,4 \pm 0,2$ & $3,6 \pm 0,2$ & 3,0 & $3,0 \pm 0,0$ & - & - & - & - \\
\hline & B & - & - & $4,4 \pm 0,2$ & $4,0 \pm 0,0$ & $4,1 \pm 0,4$ & $5,3 \pm 0,9$ & - & 5,0 \\
\hline \multirow[t]{2}{*}{ V } & A & $5,9 \pm 0,3$ & $6,1 \pm 0,1$ & 4,0 & $3,8 \pm 0,5$ & - & - & - & - \\
\hline & B & - & - & $5,3 \pm 0,5$ & $6,5 \pm 2,5$ & $3,4 \pm 0,5$ & $6,5 \pm 1,9$ & - & 3,0 \\
\hline \multirow[t]{2}{*}{ VI } & A & - & - & 6,0 & $5,8 \pm 0,2$ & - & - & - & - \\
\hline & B & - & - & $10,3 \pm 0,5$ & $11,5 \pm 0,5$ & $5,4 \pm 0,6$ & $4,0 \pm 0,7$ & - & 4,0 \\
\hline \multirow[t]{2}{*}{ VII } & A & - & - & - & - & - & - & - & - \\
\hline & B & - & - & - & - & $9,3 \pm 1,9$ & $11,3 \pm 1,3$ & - & 6,0 \\
\hline \multirow[t]{2}{*}{ VIII } & A & - & - & - & - & - & - & - & - \\
\hline & B & - & - & - & - & - & - & - & 9,0 \\
\hline \multirow[t]{2}{*}{ Total } & A & $17,2 \pm 0,4$ & $18,1 \pm 1,4$ & 21,0 & $20,6 \pm 0,7$ & - & - & - & - \\
\hline & B & - & - & $29,9 \pm 1,0$ & $31,5 \pm 2,5$ & $35,1 \pm 1,3$ & $36,5 \pm 3,1$ & - & 37,0 \\
\hline
\end{tabular}

Tabela 3. Largura (mm) da cápsula cefálica de lagartas de Nomophila sp. (Lepidoptera: Pyralidae) com V, VI, VII ou VIII estádios, alimentadas com folhas de Eucalyptus grandis de 20-30 (A) ou 50-60 (B) dias ${ }^{(1)}$.

\begin{tabular}{|c|c|c|c|c|c|c|c|c|c|}
\hline \multirow[t]{2}{*}{ Estádio $^{(2)}$} & \multirow[t]{2}{*}{ Tratamento } & \multicolumn{2}{|c|}{ Larvas de V estádio } & \multicolumn{2}{|c|}{ Larvas de VI estádio } & \multicolumn{2}{|c|}{ Larvas de VII estádio } & \multicolumn{2}{|c|}{ Larvas de VIII estádio } \\
\hline & & Macho & Fêmea & Macho $^{(3)}$ & Fêmea & Macho & Fêmea & Macho & Fêmea $^{(3)}$ \\
\hline \multirow[t]{2}{*}{ I } & $\mathrm{A}$ & $0,227 \pm 0,002$ & $0,225 \pm 0,004$ & 0,225 & $0,230 \pm 0,005$ & - & - & - & - \\
\hline & $\mathrm{B}$ & $-(4)$ & - & $0,232 \pm 0,005$ & $0,225 \pm 0,000$ & $0,232 \pm 0,005$ & $0,225 \pm 0,000$ & - & 0,225 \\
\hline \multirow[t]{2}{*}{ II } & A & $0,391 \pm 0,007$ & $0,398 \pm 0,008$ & 0,400 & $0,375 \pm 0,011$ & - & - & - & - \\
\hline & B & - & - & $0,343 \pm 0,005$ & $0,338 \pm 0,013$ & $0,350 \pm 0,005$ & $0,344 \pm 0,012$ & - & 0,350 \\
\hline \multirow[t]{2}{*}{ III } & A & $0,664 \pm 0,246$ & $0,672 \pm 0,017$ & 0,550 & $0,620 \pm 0,015$ & - & - & - & - \\
\hline & B & - & - & $0,539 \pm 0,029$ & $0,513 \pm 0,508$ & $0,504 \pm 0,025$ & $0,500 \pm 0,027$ & - & 0,525 \\
\hline \multirow[t]{2}{*}{ IV } & A & $1,002 \pm 0,014$ & $1,019 \pm 0,024$ & 0,850 & $0,880 \pm 0,033$ & - & - & - & - \\
\hline & $\mathrm{B}$ & - & - & $0,775 \pm 0,021$ & $0,725 \pm 0,025$ & $0,714 \pm 0,032$ & $0,675 \pm 0,037$ & - & 0,725 \\
\hline \multirow[t]{2}{*}{ V } & A & $1,552 \pm 0,012$ & $1,597 \pm 0,016$ & 1,150 & $1,205 \pm 0,033$ & - & - & - & - \\
\hline & B & - & - & $1,150 \pm 0,011$ & $1,138 \pm 0,358$ & $0,946 \pm 0,018$ & $1,075 \pm 0,144$ & - & 0,875 \\
\hline \multirow[t]{2}{*}{ VI } & A & - & - & 1,675 & $1,680 \pm 0,024$ & - & - & - & - \\
\hline & B & - & - & $1,600 \pm 0,017$ & $1,613 \pm 0,358$ & $1,221 \pm 0,032$ & $1,256 \pm 0,016$ & - & 1,200 \\
\hline \multirow[t]{2}{*}{ VII } & A & - & - & - & - & - & - & - & - \\
\hline & B & - & - & - & - & $1,629 \pm 0,280$ & $1,638 \pm 0,016$ & - & 1,275 \\
\hline \multirow[t]{2}{*}{ VIII } & A & - & - & - & - & - & - & - & - \\
\hline & $\mathrm{B}$ & - & - & - & - & - & - & - & 1,555 \\
\hline
\end{tabular}

${ }^{(1)}$ Condições experimentais: $24 \pm 2^{\circ} \mathrm{C}, 80 \pm 15 \%$ UR e fotofase de 12 horas. ${ }^{(2)}$ Estádio I: corpo amarelo-palha tornando-se marrom-esverdeado ao se alimentar e cápsula cefálica marrom; estádios II, III e IV: diferenciação apenas no tamanho da lagarta; estádio V: (lagartas que concluíram a fase larval) coloração do corpo semelhante aos estádios anteriores, cápsula cefálica com grande concentração de pigmentação marrom-escura; estádios VI, VII e VIII: diferenças morfológicas nas dimensões da cápsula cefálica e no comprimento do corpo. ${ }^{(3)}$ Apenas uma lagarta completou o estádio VI, em A, e o estádio VIII, em B

${ }^{(4)}$ Nenhuma lagarta completou este estádio. 
lagartas do tratamento A que deram origem a machos apresentaram maior largura da cápsula cefálica que as fêmeas. Lagartas de cinco estádios do tratamento A que originaram machos apresentaram maior largura da cápsula cefálica que aquelas que deram origem a fêmeas até o terceiro estádio. Machos de seis ou sete estádios do tratamento B apresentaram maior largura da cápsula cefálica até o quinto e quarto estádios, respectivamente. Ao final da fase larval, a largura da cápsula cefálica das lagartas que originaram fêmeas foi maior que a de machos. Mourikis \& Vassilaina-Alexopoulou (1970) observaram largura da cápsula cefálica de $0,22-0,24 \mathrm{~mm}$ no primeiro estádio e de 1,70-1,80 mm no último, para $N$. noctuella. Apesar de, inicialmente, tais valores serem semelhantes aos de Nomophila sp. criadas em mudas de E. grandis, ao final da fase larval, as lagartas criadas por aqueles autores apresentaram maior largura da cápsula cefálica que as do presente estudo.

Lagartas do tratamento A apresentaram maior comprimento inicial que aquelas do $\mathrm{B}$ a partir do terceiro estádio e maior comprimento ao final do segundo, terceiro, quarto e quinto estádios. No entanto, lagartas do tratamento B apresentaram maior comprimento que as do A nos primeiro e sexto estádios. No tratamento B, lagartas que deram origem a machos ou fêmeas apresentaram comprimento semelhante nos dois primeiros estádios. A partir dos terceiro e quarto estádios, lagartas que deram origem a fêmeas, dos tratamentos A e B, apresentaram maior comprimento do corpo que as que originaram machos (Tabela 4). O comprimento do corpo de lagartas de $N$. noctuella alimentadas com trevo-amarelo foi de 2,04-24,75 mm, nos primeiro e último estádios, respectivamente (Smith, 1942), sendo tais valores maiores que aqueles de lagartas de Nomophila sp., criadas com mudas de E. grandis com 20-30 ou 50-60 dias de idade. O maior comprimento do corpo e a menor largura da cápsula cefálica de lagartas criadas com mudas de $E$. grandis, dessas idades, em relação aos valores obtidos para lagartas criadas com outros substratos, indica que mudas de E. grandis, apesar de normalmente consumidas, não apresentam boa conversão nutricional para Nomophila sp. Isto é importante, pois a eficiência de aproveitamento do alimento para o crescimento de insetos varia com o balanço nutricional e a digestibilidade do mesmo (Gordon, 1959).

\section{Comportamento e viabilidade do estádio larval}

Logo após a eclosão, a lagarta de Nomophila sp. deixa a folha com restos de córion e busca outras mais próximas ao solo, descendo pelos caulículos das plantas de eucalipto ou penduradas pelos próprios fios de seda.

No primeiro estádio, a maioria das lagartas de Nomophila sp. raspa a porção ventral das folhas, com algumas delas penetrando em pedaços de caulículos de mudas de eucalipto com 20-30 dias e se alimentando de seus tecidos centrais, ainda tenros, o que foi, também, relatado por Flint (1922) para $N$. noctuella e por Teixeira et al. (1999) para Nomophila sp., alimentada com mudas de E. grandis com 20-30 dias de idade. Nos quarto e quinto estádios, as lagartas de cinco estádios se alimentam inclusive da nervura central da folha e, até mesmo de pecíolos e porções inteiras de caulículos em mudas de eucalipto de 20-30 dias. Nas mudas de 50-60 dias de idade, as lagartas raramente se alimentam da nervura central das folhas. A viabilidade da fase larval de Nomophila sp. foi semelhante em ambos os tratamentos, e observou-se a morte de três indivíduos em cada um deles. No tratamento A, com lagartas de cinco ou seis estádios, duas delas morreram no terceiro e uma no quarto estádio, sendo que duas morreram logo após a ecdise, uma no terceiro e outra no quarto estádio. No tratamento B, com lagartas de seis, sete e oito estádios, duas morreram durante o quinto estádio e uma no sexto. Essas lagartas apresentavam largura da cápsula cefálica dentro da média do estádio. A lagarta do sexto estádio viveu por cinco dias e a do quinto, por mais de duas semanas. A morte de lagartas alimentadas com mudas de E. grandis com 20-30 dias pode ser devido a outros fatores além do tipo de alimento, pois as mesmas apresentavam largura da cápsula cefálica abaixo da média de seus respectivos estádios. No entanto, a outra lagarta morta no terceiro estádio apresentou maior largura da cápsula cefálica que a média do estádio e morreu três dias após o início do mesmo.

O desenvolvimento de lagartas de Nomophila sp. indica que essa espécie prefere mudas de eucalipto com 20-30 dias de idade a mudas com 50-60 dias, o que concorda com Lemos et al. (1999), que observaram maior consumo de folhas jovens de E. grandis por lagartas de Thyrinteina arnobia (Lepidoptera: 
Tabela 4. Menor e maior comprimento $(\mathrm{mm}) \pm$ desvio padrão do corpo de lagartas que originaram machos e fêmeas de Nomophila sp. alimentadas com mudas de Eucalyptus grandis com 20-30 (A) ou 50-60 dias (B), segundo o total de estádios que originaram ${ }^{(1)}$.

\begin{tabular}{|c|c|c|c|c|c|c|c|c|c|}
\hline \multirow[t]{2}{*}{ Estádio $^{(2)}$} & \multirow[t]{2}{*}{ Tratamento } & \multicolumn{2}{|c|}{ Larvas de V estádio } & \multicolumn{2}{|c|}{ Larvas de VI estádio $^{(3)}$} & \multicolumn{2}{|c|}{ Larvas de VII estádio } & \multicolumn{2}{|c|}{$\underline{\text { Larvas de VIII estádio }}^{(4}$} \\
\hline & & Menor & Maior & Menor & Maior & Menor & Maior & Menor & Maior \\
\hline & & \multicolumn{8}{|c|}{ Lagartas que originaram machos } \\
\hline \multirow[t]{2}{*}{ I } & A & $1,51 \pm 0,03$ & $2,74 \pm 0,06$ & 1,65 & 2,80 & - & - & - & - \\
\hline & B & $-(5)$ & & $1,45 \pm 0,45$ & $2,76 \pm 0,14$ & $1,42 \pm 0,02$ & $2,88 \pm 0,06$ & - & - \\
\hline \multirow[t]{2}{*}{ II } & A & $3,35 \pm 0,05$ & $4,93 \pm 0,08$ & 3,55 & 5,35 & - & - & - & - \\
\hline & B & - & & $3,45 \pm 0,04$ & $4,29 \pm 0,07$ & $4,55 \pm 0,05$ & $4,19 \pm 0,06$ & - & - \\
\hline \multirow[t]{2}{*}{ III } & A & $5,40 \pm 0,10$ & $8,13 \pm 0,22$ & 5,88 & 7,05 & - & - & - & - \\
\hline & B & - & & $4,88 \pm 0,09$ & $6,31 \pm 0,07$ & $6,91 \pm 0,19$ & $6,18 \pm 0,17$ & - & - \\
\hline \multirow[t]{2}{*}{ IV } & A & $8,98 \pm 0,27$ & $16,72 \pm 0,32$ & 7,85 & 13,40 & - & - & - & - \\
\hline & B & - & & $7,48 \pm 0,36$ & $10,75 \pm 0,58$ & $10,56 \pm 0,21$ & $9,62 \pm 0,13$ & - & - \\
\hline \multirow[t]{2}{*}{ V } & A & $17,74 \pm 0,22$ & $24,67 \pm 0,65$ & 14,83 & 18,20 & - & - & - & - \\
\hline & B & - & - & $11,30 \pm 0,68$ & $15,95 \pm 0,96$ & $14,99 \pm 0,19$ & $14,23 \pm 0,23$ & - & - \\
\hline \multirow[t]{2}{*}{ VI } & A & - & - & 18,83 & 24,13 & - & - & - & - \\
\hline & B & - & - & $18,58 \pm 0,88$ & $25,46 \pm 0,69$ & $20,72 \pm 0,37$ & $19,21 \pm 0,38$ & - & - \\
\hline \multirow[t]{3}{*}{ VII } & A & - & - & - & - & - & - & - & - \\
\hline & $\mathrm{B}$ & - & - & - & - & - & $26,09 \pm 0,74$ & - & - \\
\hline & & \multicolumn{8}{|c|}{ Lagartas que originaram fêmeas } \\
\hline \multirow[t]{2}{*}{ I } & A & $1,49 \pm 0,04$ & $2,68 \pm 0,04$ & $1,54 \pm 0,03$ & $2,65 \pm 0,04$ & - & - & - & - \\
\hline & B & $-(5)$ & - & $1,56 \pm 0,01$ & $2,85 \pm 0,20$ & $1,41 \pm 0,06$ & $2,84 \pm 0,08$ & 1,30 & 2,83 \\
\hline \multirow[t]{2}{*}{ II } & A & $3,34 \pm 0,05$ & $4,95 \pm 0,10$ & $3,35 \pm 0,12$ & $4,78 \pm 0,12$ & - & - & - & - \\
\hline & B & - & - & $3,25 \pm 0,03$ & $4,01 \pm 0,16$ & $3,28 \pm 0,03$ & $4,24 \pm 0,08$ & 3,35 & 3,86 \\
\hline \multirow[t]{2}{*}{ III } & A & $5,33 \pm 0,10$ & $7,85 \pm 0,22$ & $5,30 \pm 0,16$ & $7,57 \pm 0,18$ & - & - & - & - \\
\hline & B & - & - & $4,45 \pm 0,10$ & $6,64 \pm 0,36$ & $4,51 \pm 0,08$ & $6,14 \pm 0,19$ & 4,63 & 6,20 \\
\hline \multirow[t]{2}{*}{ IV } & A & $8,78 \pm 0,23$ & $17,29 \pm 0,62$ & $8,58 \pm 0,15$ & $14,85 \pm 0,33$ & - & - & - & - \\
\hline & B & - & - & $7,35 \pm 0,05$ & $10,65 \pm 0,20$ & $6,75 \pm 0,32$ & $9,81 \pm 0,22$ & 6,40 & 10,45 \\
\hline \multirow[t]{2}{*}{$\mathrm{V}$} & A & $18,45 \pm 1,43$ & $25,75 \pm 0,57$ & $15,57 \pm 0,40$ & $19,58 \pm 0,37$ & - & - & - & - \\
\hline & B & - & - & $11,84 \pm 0,70$ & $18,35 \pm 1,50$ & $10,92 \pm 0,38$ & $14,77 \pm 0,54$ & 10,70 & 13,50 \\
\hline \multirow[t]{2}{*}{ VI } & A & - & - & $20,56 \pm 0,26$ & $27,96 \pm 0,69$ & - & - & - & - \\
\hline & B & - & - & $21,93 \pm 0,28$ & $28,65 \pm 0,65$ & $15,83 \pm 0,69$ & $19,58 \pm 0,54$ & 14,85 & 17,63 \\
\hline \multirow[t]{2}{*}{ VII } & A & - & - & - & - & - & - & - & - \\
\hline & B & - & - & - & - & $21,08 \pm 0,51$ & $26,68 \pm 0,67$ & 18,45 & 21,40 \\
\hline \multirow[t]{2}{*}{ VIII } & A & - & - & - & - & - & - & - & - \\
\hline & B & - & - & - & - & - & - & 22,33 & 27,95 \\
\hline
\end{tabular}

(1)Condições experimentais: $24 \pm 2^{\circ} \mathrm{C}, 80 \pm 15 \%$ UR e fotofase de 12 horas. ${ }^{(2)}$ Estádio I: corpo amarelo-palha tornando-se marrom-esverdeado ao se alimentar e cápsula cefálica marrom; estádios II, III e IV: diferenciação apenas no tamanho da lagarta; estádio V: (lagartas que concluíram a fase larval) coloração do corpo semelhante aos estádios anteriores, cápsula cefálica com grande concentração de pigmentação marrom-escura; estádios VI, VII e VIII: diferenças morfológicas nas dimensões da cápsula cefálica e no comprimento do corpo. ${ }^{(3)}$ Das lagartas que originaram machos, apenas uma lagarta completou este estádio no tratamento A. ${ }^{(4)}$ Das lagartas que originaram fêmeas, apenas uma completou este estádio no tratamento B. ${ }^{(5)} \mathrm{Nenhuma} \mathrm{lagarta}$ completou este estádio.

Geometridae), nos terceiro e quarto estádios e com Drooz (1970), que mostrou que lagartas de Ennomos subsignarius (Lepidoptera: Geometridae) nos primeiro e quarto estádios preferem folhas jovens de carvalho e nogueira. Com o crescimento, as mudas de eucalipto tornam-se mais enrijecidas (Anjos et al., 1986), apresentam aumento do teor de celulose e modificações no balanço água-nutrientes, além de variações no valor nutricional, mesmo para plantas de mesma espécie (Waldbauer, 1968), pois Evans (1939) mostrou que a variação da idade de folhas de couve resulta em mudanças na sua digestibilidade para uma espécie do gênero Pieris. Além disso, Peres Filho (1989) observou que a raspagem e o corte de folhas jovens por lagartas de T. arnobia, nos três primeiros estádios, é conseqüência da dificuldade 
das mesmas em cortar folhas com maior grau de dureza, o que reforça a hipótese de que a preferência alimentar por folhas jovens pode estar relacionada aos aspectos morfológicos das mesmas. No entanto, outros fatores como modificações no balanço de nutrientes e na concentração de nitrogênio, em razão da variação do conteúdo de água com o desenvolvimento das mudas de $E$. grandis, podem alterar a dinâmica populacional de insetos (Ohmart et al., 1985). Assim, quando o alimento torna-se mais digestível há maior probabilidade de surgimento de surtos populacionais de insetos. Por outro lado, alimentos com menor digestibilidade podem aumentar a duração da fase larval de insetos e reduzir o crescimento populacional de pragas, devido ao aumento das chances de predação ou parasitismo, além de reduzir a fertilidade de seus adultos (Carne, 1966). Essas evidências reforçam a necessidade de se utilizar adubação adequada para mudas de E. grandis como forma de acelerar seu desenvolvimento e tornálas, morfologicamente, menos adequadas para o desenvolvimento e a reprodução de Nomophila sp.

\section{Conclusões}

1. Nomophila sp. prefere mudas de Eucalyptus grandis com 20-30 dias a mudas com 50-60 dias de idade durante seu desenvolvimento.

2. Lagartas alimentadas com mudas de eucalipto com 50-60 dias de idade apresentam maior número e duração dos estádios.

3. A duração da fase larval é menor em lagartas alimentadas com mudas de eucalipto com 20-30 dias de idade.

4. Lagartas alimentadas com mudas de eucalipto com 20-30 dias de idade apresentam maior largura da cápsula cefálica, exceto no primeiro estádio.

5. Lagartas alimentadas com mudas de eucalipto com 20-30 dias de idade apresentam maior comprimento inicial a partir do terceiro estádio e maior comprimento ao final do segundo, terceiro, quarto e quinto estádios.

6. Lagartas de Nomophila sp. apresentam comportamento diferenciado quando se alimentam com mudas de 20-30 e de 50-60 dias de idade, mas a viabilidade de seus indivíduos é semelhantes nos dois tratamentos.

\section{Referências}

ANJOS, M.; LUDWIG, A.; SANTOS, G. P.; MOREIRA, J. F. Eficiência de três produtos químicos e de um processo mecânico no controle de lagartas-rosca em mudas de Eucalyptus grandis Hill ex-Maiden. Revista Árvore, Viçosa, v. 5, n. 2, p. 218-223, 1981.

ANJOS, N.; SANTOS, G. P.; ZANUNCIO, J. C. Pragas do eucalipto e seu controle. Informe Agropecuário, Belo Horizonte, v. 12, n. 141, p. 50-58, 1986.

BERTI FILHO, E. Insetos associados às plantações de espécies do gênero Eucalyptus nos Estados da Bahia, Espírito Santo, Mato Grosso do Sul, Minas Gerais e São Paulo. Piracicaba : ESALQ/USP, 1981. 176 p. Tese de Livre Docência.

CARNE, P. B. Ecological characteristics of the eucalyptdefoliating chrysomelid Paropsis atomaria 01. Australian Journal of Zoology, Australia, v. 14, p. 647-672, 1966.

DROOZ, A. T. The elm spanworm (Lepidoptera: Geometridae): how several natural diets affect its biology. Annals of the Entomological Society of America, Columbus, v. 63, n. 2, p. 391-397, 1970.

EVANS, A. C. The utilization of food by certain lepidopterous larvae. Transactions Entomological Society of London, Londres, v. 89, p. 13-22, 1939.

FELT, P. Nomophila noctuella Schiff. Order Lepidoptera, Family Pyralidae. Canadian Entomologist, Guelph, v. 25, p. $129-134,1893$.

FLINT, W. P. Studies of the life history of Nomophila noctuella. Annals of the Entomological Society of America, Columbus, v. 15, p. 154-156, 1922.

GALLO, D.; NAKANO, O.; SILVEIRA NETO, S.; CARVALHO, R. P. L.; BATISTA, G. C.; BERTI FILHO, E.; PARRA, J. R. P.; ZUCCHI, R. A.; ALVES, S. B. Manual de entomologia agrícola. São Paulo : Agronômica Ceres, 1978. $531 \mathrm{p}$.

GORDON, H. T. Minimal nutritional requirements of the German roach, Blattella germanica. Annals of the New York Academy of Science, Nova York, v. 77, p. 290 $351,1959$.

JOHNSON, N. E.; DUFFIELD, J. Larvae of Nomophila noctuella feeding on Douglas-fir seedlings. Journal of Economic Entomology, Lanham, v. 54, n. 6, p. 12581259, 1961. 
KRUG, H. P. Alguns problemas em viveiros de Pinus spp. Silvicultura em São Paulo, São Paulo, v. 1, n. 2, p. 4757, 1963.

LEMOS, R. N. S.; CROCOMO, W. B.; FORTI, L. C.; WILCKEN, C. F. Seletividade alimentar e influência da idade da folha de Eucalyptus spp. para Thyrinteina arnobia (Lepidoptera: Geometridae). Pesquisa Agropecuária Brasileira, Brasília, v. 34, n. 1, p. 7-10, 1999.

MOURIKIS, P. A.; VASSILAINA-ALEXOPOULOU, P. Some observations on the biology of Nomophila noctuella under laboratory conditions. Entomologist, London, v. 103, p. 296-303, 1970.

OHMART, C. P.; STEWART, L. G.; THOMAS, J. R Effects of food quality, particulary nitrogen concentrations, of Eucalytus blakelyi foliage on the growth of Paropsis atomaria larvae (Coleoptera: Chrysomelidae). Oecologia, Berlin, v. 65, n. 4, p. 543-549, 1985.

PAIVA, H. N.; GOMES, J. M. Viveiros florestais. Viçosa : UFV, Imprensa Universitária, 1995. 56 p.

PERES FILHO, O. Bioecologia de Thyrinteina arnobia (Stoll, 1782) (Lepidoptera, Geometridae) mantida em duas espécies de Eucalyptus (Myrtaceae). Piracicaba : ESALQ-USP, 1989. 163 p. Tese de Doutorado.

REIS, M. S.; HODGES, C. B. Forest development and research - Brazil, status of forest diseases and insects in Latin American. Brasília : Brazilian Institute for Forestry Development, United Nations Development Programme and Food and Agriculture Organization of the United Nations, 1976. 10 p. (Field Document, 12).
SANTOS, G. P.; ANJOS, N.; ZANUNCIO, J. C. Pragas da seringueira e seu controle. Informe Agropecuário, Belo Horizonte, v. 11, n. 121, p. 44-52, 1985.

SANTOS, G. P.; COSENZA, G. W.; ALBINO, J. C. Biologia de Spodoptera latifascia (Walker, 1856) (Lepidoptera: Noctuidae) sobre folhas de eucalipto. Revista Brasileira de Entomologia, São Paulo, v. 24, n. 2, p. 153-155, 1980.

SILVA, A. G. A.; GOLÇALVES, C. R.; GALVÃO, D. M.; GONÇALVES, A. J. L.; GOMES, J.; SILVA, M. M.; SIMONE, L. Quarto catálogo dos insetos que vivem em plantas do Brasil, seus parasitos e predadores. Rio de Janeiro : Departamento de Defesa e Inspeção Agropecuária, 1968. v. 1.

SMITH, R. C. Nomophila noctuella as a grass and alfafa pest in Kansas (Lepidoptera: Pyralidae). Journal of the Kansas Entomological Society, Manhattan, v. 15, p. 2534, 1942.

TEIXEIRA, C. A. D.; ZANUNCIO, J. C.; SOSSAI, M. F.; PRATISSOLI, D. Biologia da lagarta-rosca Nomophila sp. (Lepidoptera: Pyralidae) em mudas de Eucalyptus grandis (Myrtaceae): I - Fases de ovo e larva. Revista Árvore, Viçosa, v. 23, n. 1, p. 65-68, 1999.

WALDBAUER, G. P. The consumption and utilization of food by insects. Advances in Insect Physiology, Cambridge, v. 5, p. 229-289, 1968.

ZANUNCIO, J. C.; ALVES, J. B.; SANTOS, G. P.; CAMPOS, W. O. Levantamento e flutuação populacional de lepidópteros associados à eucaliptocultura: VI. Região de Belo Oriente, Minas Gerais. Pesquisa Agropecuária Brasileira, Brasília, v. 28, n. 10, p. 1121-1127, 1993. 